\title{
Understanding divergence in India: a political economy approach
}

\author{
Chetan Ghate* \\ Indian Statistical Institute, New Delhi, India, and Max Planck Institute for Economics, Jena, Germany
}

\begin{abstract}
We construct a simple political economy model with imperfect capital markets to explain infrastructure investments across Indian states. The model predicts that: i) the fixed cost of accessing the modern sector, ii) the initial stock of infrastructure, iii) median voter wealth, and iv) corruption, can all potentially explain why different states have different levels of infrastructure investments. The theoretical model is motivated by recent empirical work on India that argues that the reason per-capita income across Indian states has diverged is because of the distribution of infrastructure investments.
\end{abstract}

Keywords: public investment; positive political economy; median voter theorem; Indian economic growth

JEL codes: P16: political economy of capitalism; E62: fiscal policy; O40 economic growth

\section{Introduction}

A fundamental question that confronts policy setters is whether there is a tendency for the poorer regions of a country to grow faster than the richer regions leading to a convergence in living standards. Such "balanced" growth is of central concern as it enables regions to share more broadly the benefits of economic growth. In the Indian context, recent work suggests that per-capita income across states has not converged. Rather, Indian states have stratified towards a bimodal distribution suggesting the existence of twin peak dynamics (Bandopadhyay 2004). In particular, Bandopadhyay (2004) identifies two convergence clubs in India over the 1965-1998 period; one club at $50 \%$ and another at $125 \%$ of the national income average. Bandopadhyay (2004) shows that infrastructure spending strongly explains the emergence of the lower convergence club. Bandopadhyay (2004) also finds that development expenditures on education are a strong explanatory variable for the observed polarization across Indian states over the time period 1965-1988. These results are consistent with other empirical work in the Indian context that has supported divergence (Dasgupta et al. 2000, Marjit and Mitra 1996, Datta and Ravallion 2002).

Figure 1 plots an infrastructure index using principal components analysis based on Indian state-wise development expenditure data against the average growth of real per-capita GDP between 1980 and 1998. We interpret infrastructure to include social as well as physical infrastructure. The index is conducted for 25 Indian states for which data between 1980 and 1998 are available. The development expenditure data incorporate both economic and social expenditure categories from both the revenue and capital accounts. These data are obtained from various state fiscal documents that contain disaggregated data for several expenditure categories. These include: 1) education, sports, art, and culture; 2) medical, public health, and family welfare; 3) water supply and sanitation; 4) housing; 5) urban development; 6) agriculture and allied activities; 7) rural development; 8) energy; 9) industry and minerals; 10) transport and communication; 11)

*Email: cghate@isid.ac.in 


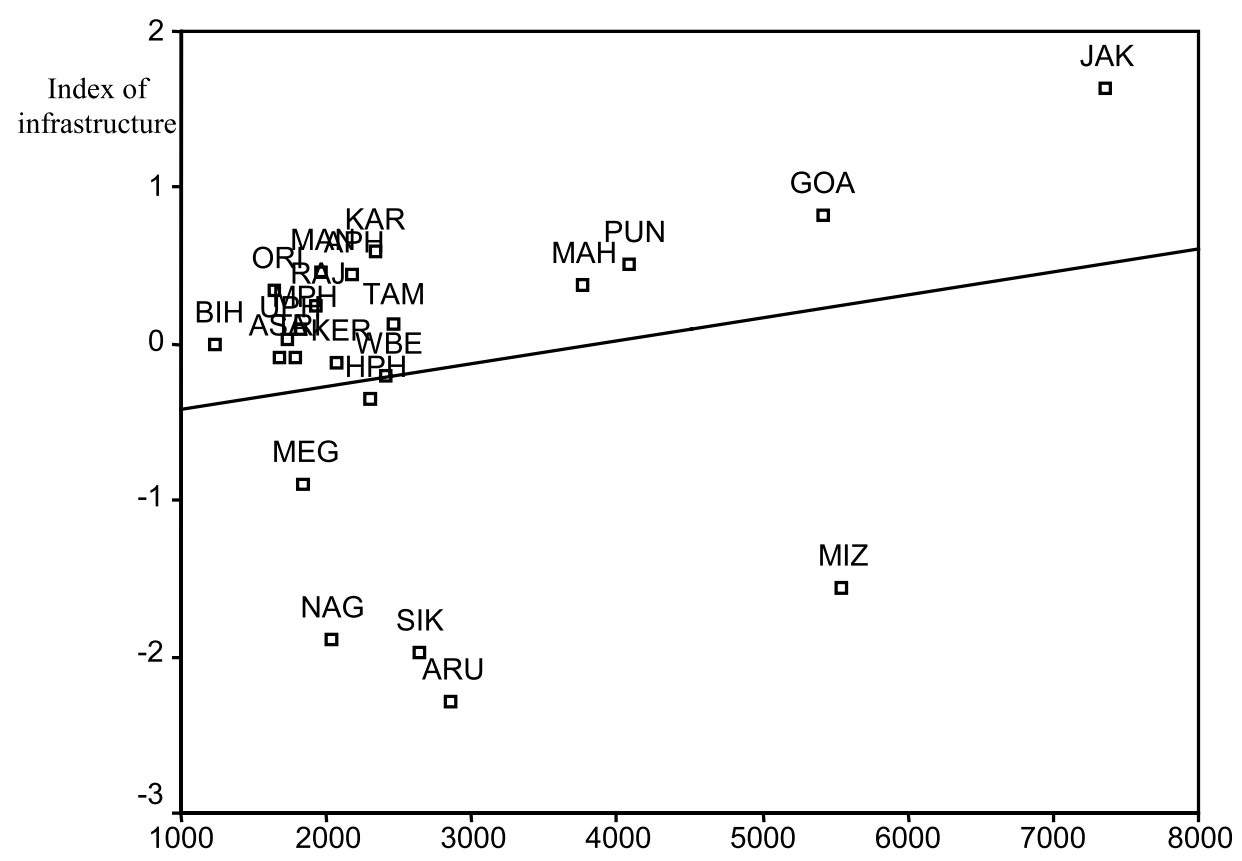

Real per capita gross state domestic product across Indian states (1980-81 to 1997-98)

Figure 1. Infrastructure index and real per capita GSDP.

social security; and 12) welfare. We focus on the period after 1980 due to the unavailability of a comprehensive state-wise development expenditure data set before 1980. The real gross state domestic product (RGSDP) data have been obtained from the Economic and Political Weekly Foundation dataset (2003). As Figure 1 shows, there is a positive relationship between the infrastructure index and real per-capita state GDP between 1980-1981 and 1997-1998 (slope coefficient $=+.233$ ). This suggests that richer states have better infrastructure.

If richer states in India have better infrastructure, what policy changes would incentivize politicians to spend more on infrastructure investment? To answer this question, we construct a simple theoretical model along the lines of Galor and Zeira (1993) to understand the political economy of variations in infrastructure/development expenditures across Indian states. We assume that agents can engage in one of two activities: i) a subsistence activity which yields a fixed return; and ii) a modern activity that requires a fixed investment and generates a return that depends on the stock of infrastructure in the economy. Politicians tax the modern sector and use tax proceeds to finance two policies under a balanced budget: a per-head consumption subsidy (which is unproductive by construction), and productive infrastructure. Given the setup, we show that the median voter theorem applies and in equilibrium and either a zero subsidy policy (which we call $\boldsymbol{P}^{*}$ policies) or a positive subsidy policy (which we call $\boldsymbol{P}^{0}$ policies) are offered. We show that the zero subsidy policy is the equilibrium policy choice if and only if the median voter, $w^{m}$, can access the modern sector at $\boldsymbol{P}^{*}$. Importantly, we show that the zero subsidy policy implies more infrastructure investment than the positive subsidy policy.

We then augment the model to incorporate corruption. We interpret corruption in the model as a leakage. To formalize ideas, suppose ' $I$ ' is the amount that is planned for investment in infrastructure. Let the parameter $\theta \in[0,1]$ denote the extent of corruption, where $\theta=1$ corresponds to full wastage. We assume that for every rupee set aside for such an activity, only $1-\theta$ is actually 
invested, with the remaining fraction, $\theta$, wasted. One can think of such leakages as a direct result of the presence of corrupt officials/personnel/public employees in charge of disbursing tax proceeds for infrastructure spending. As in the case of infrastructure investments, we assume that there are also leakages involved in the disbursement of the per-head consumption subsidy, $S$. In particular, for every rupee of planned $S$, a fraction $\theta$ is wasted in the disbursement of the consumption subsidy. Given this, suppose there are two levels of corruption, $\theta_{1}$ and $\theta_{2}$, such that $\theta_{1}>\theta_{2}$. Further, suppose that a positive subsidy policy - the $P^{0}$ policies - is an equilibrium policy choice under $\theta_{2}$. We show that $P^{0}$ policies will be the equilibrium policy choice under $\theta_{1}$. In other words, higher corruption makes it more likely for positive subsidies and lower infrastructure investment to obtain as equilibrium policies.

In sum, consistent with the empirical evidence reported in Figure 1, the theoretical model predicts the following variables which can potentially account for differential infrastructure investment across Indian states: i) the fixed cost of accessing the modern sector; ii) the initial stock of infrastructure; iii) median voter wealth; and iv) corruption. These variables offer potential explanations for the distribution of infrastructure investments and therefore why per-capita income across Indian states has diverged. The paper is structured as follows. The next section formalizes the model. Section 3 discusses the policy implications of the model and concludes.

\section{The model}

The economy is populated with a continuum of agents with unit mass. Each agent is characterized by its wealth level, $w$, where $w$ has the distribution function, $F(w)$, with support $[w, \bar{w}]$. Agents can engage in one of two activities: i) a subsistence activity which yields a fixed return, $a>0$, and ii) a modern activity which requires a fixed investment, $F$, and generates return, $R$. $F$ denotes the fixed cost of accessing the modern sector. We assume that the return, $R$, in the modern activity depends on the stock of infrastructure, $G$, in the economy. We assume that $R(G)$ is increasing and strictly concave in $G$.

The economy has an initial capital stock, $G_{0}$, which can be augmented using tax proceeds in the current period. Throughout, we assume that the return from the subsistence sector is strictly dominated by investment in the subsistence sector, i.e.,

$$
R\left(G_{0}\right)-a>0 .
$$

Let $I$ be the amount of investment on infrastructure, as in Barro (1990). For every rupee set aside for infrastructure investments, a fraction, $\theta \in[0,1]$, is wasted, while the remaining fraction, $1-$ $\theta$, is invested in development projects. One can think of such leakages as a direct result of the presence of corrupt officials or personnel in charge of disbursing development funds, as in Mauro (1995). Consequently, given planned investment, $I$, the stock of infrastructure is given by

$$
G=G_{0}+I(1-\theta)
$$

Denote

$$
\pi(G)=R(G)-F
$$

to represent the payoff to an agent from the modern activity when ' $T$ ' is the planned investment on infrastructure. We assume that there is a profit tax on the return from investing in the modern sector. However, to keep the model simple, we assume that the return from the subsistence sector is not taxed. Finally, besides choosing $I$, the government in place also disburses a lump 
sum per-head consumption subsidy, $S>0$, to agents in the subsistence sector. As in the case of infrastructure investment, we assume that for every rupee of planned $S$, a fraction, $\theta$, is wasted in the disbursement of the subsidy. This implies that agents receive a payoff of $S(1-\theta)$ if $S$ rupees are earmarked for the consumption subsidy.

A fiscal policy, $P$, in this setting is the policy tuple $\{t, I, S\}$, where $t \in[0,1]$ denotes a proportional tax on profits in the modern sector, $I$ is the level of infrastructure investment, and $S$ is the level of the consumption subsidy. For a policy $P$, if an agent with wealth ' $w$ ' decides to opt for the subsistence sector, his net payoff will be $S(1-\theta)+a$. Further, if he decides to opt for the modern sector, we assume that he needs to invest an amount $F>0$. If $w<F$, the agent needs to borrow the residual amount, $z=F-w$, from the credit market.

Following Holmstrom and Tirole (1997), we assume the presence of moral hazard of the following form: any agent has the option of investing the amount, $F$, in an alternative project. This project yields a non-diversifiable return, $B$, to the agent, and nothing to the investor. We assume that $B<F$ and will refer to the alternative project as the unproductive project. Productive investment on the other hand leads to a gross return of $R(G)$. Agents need to pay back ' $z$ ' to lenders and then have to pay a tax, $t \cdot \pi(G)$, to the government. We are thus assuming an interest rate of 0 . The net return from investing in the modern sector yields a payoff,

$$
R(G)-(F-w)-t \pi(G)=(1-t) \pi(G)+w .
$$

Since an agent will be able to obtain a loan if he invests productively, we must have

$$
(1-t) \pi(G)+w \geq B
$$

Thus, for such an agent, investing in the modern activity yields a payoff of $(1-t) \pi(G)+w+S$. Since $B<F$, an agent with wealth, $w>F$, will always invest productively earning a payoff of $(1-t) \pi(G)+w+S$ as well. Given a policy $P=\{t, I, S\}$, an agent with wealth, $w$, will prefer to invest in the modern sector if and only if equation (5) is satisfied and if

$$
(1-t) \pi(G) \geq a
$$

It is clear that for an agent with wealth, $w$, if equations (5) and (6) are satisfied, then these equations will be satisfied for any higher wealth agent as well. Thus, given the policy, $P=\{t, I, S\}$, the set of agents that will be in the modern sector is given by the set of wealth levels $\left[w^{*}, \bar{w}\right]$, where $w^{*}$ is the minimum level of wealth for which equations (5) and (6) are satisfied.

Given the policy triple, $P=\{t, I, S\}$, the total tax collection, $T$, is given by

$$
T=t \pi(G)\left(1-F\left(w^{*}\right)\right) .
$$

The policy triple, $P=\{t, I, S\}$, balances the budget if and only if

$$
t \pi(G)\left(1-F\left(w^{*}\right)\right)=I+S .
$$

Let $w^{m}$ be the median wealth holder and let $P^{m}=\left\{t^{m}, I^{m}, S^{m}\right\}$ be the policy that is the most preferred by this median wealth holder. We can now characterize this policy. Choose $P=\{t, I$, $0\}$ to maximize $(1-t) \pi(G)$ subject to the balanced budget constraint of the government, equation (8). Let $P^{*}=\left\{t^{*}, I^{*}, 0^{*}\right\}$ denote the optimal solution. Because of equation (1), we have $\pi\left(G_{0}\right)>0$, and thus it is immediate that one has $(1-t) \pi(G)>a$. Now choose $P=\{t, I, S\}$ to maximize $S=$ $t \pi(G)\left(1-F\left(w^{*}\right)\right)-I$, subject to the constraint that the policy balances the budget and $w^{*}$ satisfies 


$$
(1-t) \pi(G)=B-w^{*}
$$

Let $P^{0}=\left\{t^{0}, I^{0}, S^{0}\right\}$ solve this maximization problem. We assume the existence of two political parties who compete in offering policies so as to obtain the larger share of votes. As it turns out that even though the policy space is multi-dimensional, the median voter applies to the present setting.

Proposition 1. The median voter theorem applies and in equilibrium either the policy $P^{*}$, or the policy $P^{0}$ is offered.

Proof. The proof of the Proposition is straightforward. First, assume that at the equilibrium policy choice, $P=\{t, I, S\}$, the median voter is in the modern sector. The income of the median voter under this policy is

$$
Y^{m}=(1-t) \pi(G)+S(1-\theta)+w^{m} .
$$

Let $\mu$ denote the mass of agents in the modern sector. Since the policy must balance the budget, we have $t \mu \pi(G)=I+S$, where $\mu=1-F\left(w^{*}\right)$, and $w^{*}$ satisfies $(1-t) \pi(G)=B-w^{*}$. Thus,

$$
Y^{m}=\pi(G)-\frac{I+S}{\mu}+S(1-\theta)+w^{m}
$$

Since $\mu<1$, if $S>0, Y^{m}<\pi(G)-\frac{1}{\mu}+w^{m}$. We now argue that the subsidy amount, $S$, cannot be positive. Consider the alternative, $P^{\prime}$ such that $I^{\prime}=I, S^{\prime}=0$, and $t^{\prime}<t$ such that $t^{\prime} \mu \pi(G)=I$ where $\left(1-t^{\prime}\right) \pi(G)=B-w^{\prime}$. Clearly, if $\mu^{\prime}>\mu$, since $t^{\prime}<t$, the income of the median voter under this policy is given by $\pi(G)-\frac{1}{\mu^{\prime}}+w^{\prime m}$ which is strictly greater than his earlier income. Thus, $S$ must equal zero. The proof is now complete noting that the definition of $P^{*}$ maximizes $(1-$ $t) \pi(G)$. Now if at the equilibrium policy choice, the median voter is in the traditional sector, then his income is equal to $a+S(1-\theta)+w^{m}$. The optimal policy then maximizes $S(1-\theta)$, subject to the constraint that the policy balances the budget implying that the policy choice is $P^{0}$.

Which of these policies will result in equilibrium? This will depend upon the median voter's wealth level, $w^{m}$, in relation to the fixed cost of investment, $F$, that allows access to the modern sector. The next proposition provides a complete characterization. We say that an agent with wealth $w$ can access the modern sector at the policy $P$ if at $P$ equations (5) and (6) are satisfied for any agent, $w$.

Proposition 2. $P^{*}$ is the equilibrium policy choice if and only if the median voter, $w^{m}$, can access the modern sector at the policy, $P^{*}$.

Proof. The necessity part of the proof is obvious. We show that if the median voter can access the modern sector at this policy, $P^{*}$, then $P^{*}$ is the equilibrium choice. To see this, note that there is an agent with high enough wealth, say $\bar{w}$, who definitely prefers the policy $P^{*}$ to the policy $P^{0}$. For this agent, we must have 


$$
\left(1-t^{*}\right) \pi\left(G^{*}\right)+\bar{w}>\left(1-t^{0}\right) \pi\left(G^{0}\right)+\bar{w}+S^{0}(1-\theta) .
$$

Since the median voter can access the modern sector at $P^{*}$, he can thus ensure himself a payoff of $\left(1-t^{*}\right) \pi\left(G^{*}\right)+w^{m}$, under the $P^{*}$ policy which by the above inequality is strictly greater than $\left(1-t^{0}\right) \pi\left(G^{0}\right)+S^{0}(1-\theta)+w^{m}$, the payoff under the $P^{0}$ policy. This proves the result.

We now provide a sufficient condition under which $P^{*}$ is the equilibrium choice.

Proposition 3. Suppose $R\left(G_{0}\right)-F+w^{m}>B$, then in equilibrium policy $P^{*}$ is chosen.

Proof. Since $R\left(G_{0}\right)-F+w^{m}>B$, at the null policy, $t=I=S=0$, the median voter can access the modern sector. Moreover, from equation (1), it is preferable for the median voter to choose the modern sector at this null policy. Since the $P^{*}$ policy maximizes the expression, $(1-t) \pi(G)$, subject to government budget constraint, it must be that $\left(1-t^{*}\right) \pi\left(G^{*}\right)>\pi\left(G_{0}\right)$. Since $\pi\left(G_{0}\right)>B-w^{m}$ (by hypothesis), we thus have

$$
\left(1-t^{*}\right) \pi\left(G^{*}\right)>B-w^{m} .
$$

Thus, at $P^{*}$, equations (5) and (6) are both satisfied for $w^{m}$ and thus by Proposition (3), $P^{*}$ is the equilibrium choice.

Since under the policy $P^{*}$, the subsidy amount is zero, we will refer to this policy as the productive policy, while under the policy $P^{0}$, the subsidy amount is positive. Moreover, as the following proposition shows, investment under the $P^{0}$ policy will be lower compared to investment under the $P^{*}$ policy. $P^{0}$ will thus be referred to as the unproductive policy. Let $I^{*}$ (respectively, $I^{0}$ ) be associated with the policy $P^{*}$ (respectively, $\left.P^{0}\right)$. Then the following proposition holds.

Proposition 4. Suppose $\pi(G)$ is concave, then $I^{*}>I^{0}$.

Proof. Let $\left\{t^{*}, I^{*}\right\}$ be the optimal no subsidy policy, and let $\mu^{*}$ be the mass of agents who are in the modern sector with this policy. Let $\left\{t^{0}, I^{0}\right\}$ be the optimal positive subsidy policy and let $\mu^{0}$ be the associated measure of agents who are in the modern sector with this positive subsidy policy. It is possible to show that $\mu^{*}>\mu^{0}$. We now show that $I^{*}>I^{0}$ for any $G_{0}$. For any given $\mu$, suppose we want to maximize $(1-t) \pi\left(G_{0}+I(1-\theta)\right)$, subject to $t \mu \pi\left(G_{0}+I(1-\theta)\right)=I$. The first order condition is given by

$$
\pi^{\prime}(G)=\frac{1}{\mu(1-\theta)} .
$$

Let $I^{*}(\mu)$ be a solution to equation (10). Since $\pi(\cdot)$ is strictly concave, $I^{*}(\mu)$ is increasing in $\mu$ whenever $I^{*}(\mu)>0$. For a given $\mu$, now consider the following maximization problem: maximize $t \mu \pi\left(G_{0}+I(1-\theta)\right)-I$. The first order condition is

$$
\mu \pi\left(G_{0}+I(1-\theta)\right)+\frac{d I}{d t}\left[t \mu \pi^{\prime}(G)(1-\theta)-1\right]=0,
$$

where $\frac{d I}{d t}$ is given from the equation

$$
(1-t) \pi\left(G_{0}+I(1-\theta)\right)+w=B,
$$


and $1-F(w)=\mu$. Totally differentiating equation (12) and noting that $\mu$ is fixed (and thus $w$ is fixed) implies

$$
\frac{d I}{d t}=\frac{\pi(G)}{(1-t) \pi^{\prime}(G)(1-\theta)} .
$$

Utilizing equations (13) in (11), and simplifying yields

$$
\pi^{\prime}(G)=\frac{1}{\mu(1-\theta)} .
$$

Since equations (10) and (14) are the same equations, for a given $\mu$, the solution to (14) is the same as that of $(10)$ and equals $I^{*}(\mu)$. Since $\mu^{*}$ under the $P^{*}$ policy is greater than $\mu^{0}$, it follows that

$$
I^{*}\left(\mu^{*}\right)>I^{0}\left(\mu^{0}\right)
$$

Proposition (4) suggests that investment in infrastructure under $P^{*}$ policies will be greater than investment under $P^{0}$ (positive subsidy, or unproductive) policies. This suggests that if the mass of entrepreneurs in the modern sector exceeds the mass of entrepreneurs in the subsistence sector, higher investment obtains. Finally, Proposition (3) provides a sufficient condition that allows the median voter to be able to access the modern sector. In other words, if the median voter can invest in the modern sector, then his optimal policy is $P^{*}$. This implies that

$$
\underline{w}<w_{\text {positive-subsidy }}^{m}<w^{*}\left(G_{0}\right)<w_{\text {zero-subsidy }}^{m}<\bar{w} .
$$

Equation (16) implies that there exists some $w^{*}$, such that if $w^{m}>w^{*}\left(G_{0}\right)$, then the optimal policy is $P^{*}$, with no subsidy. If $w^{m}<w^{*}\left(G_{0}\right)$, then the optimal policy is $P^{0}$, with a subsidy. Note that $w^{*}\left(G_{0}\right)$ is falling in the initial stock of infrastructure, $G_{0}$. This means that the higher the stock of infrastructure, the easier it is for the median voter to access the modern sector: i.e., $w>w^{*}$.

We now focus on the impact of corruption on optimal policy choices. It may be of interest to know how the optimal policy changes if the extent of leakage, as captured by $\theta$, changes.

Proposition 5. Let $\theta_{1}>\theta_{2}$, and suppose policy $P^{0}$ is an equilibrium policy choice under $\theta_{2}$, then $P^{0}$ is the equilibrium policy choice under $\theta_{1}$.

Proof. It is immediate that under the $P^{*}$ policy, the net income of an agent is greater when the leakage, $\theta$, is less, i.e.,

$$
\left(1-t^{*}\left(\theta_{2}\right)\right) \pi\left(G^{*}\left(\theta_{2}\right)\right)>\left(1-t^{*}\left(\theta_{1}\right)\right)\left(\pi\left(G^{*}\left(\theta_{1}\right)\right)\right.
$$

Since under $\theta_{2}$ the equilibrium policy choice is $P^{0}$, by Proposition (2), we know that the median voter cannot access the modern sector under $P^{*}$ at $\theta_{2}$. Since $\theta_{1}>\theta_{2}$, the median voter will not be able to access the modern sector at $P^{*}$ and $\theta_{1}$ as well.

Proposition 5 suggests that if corruption is higher, then positive subsidy policies are more likely to obtain in equilibrium. This is because more leakage makes the constraint, $R(G)-F>a$, less likely to be satisfied, which implies that agents cannot access the modern sector. 
In sum, consistent with the empirical evidence reported in Figure 1, the theoretical model predicts the following variables which can potentially account for differential infrastructure investment across Indian states: i) the fixed cost of accessing the modern sector; ii) the initial stock of infrastructure; iii) median voter wealth; and iv) corruption or leakages in infrastructure spending. In the next section we conclude with some policy recommendations based on the theoretical model assessing the potential effectiveness of each of these measures on regional growth.

\section{Discussion and conclusion}

Recent empirical work on India argues that the reason per-capita income across Indian states has diverged in the last few decades is because of the distribution of infrastructure investments. However, virtually no study - to the best of our knowledge - has attempted to provide a theoretical explanation for why infrastructure investments across Indian states vary, and how exogenous policy changes can incentivize politicians to spend more on infrastructure investments.

The model in the previous section suggests that the way to incentivize higher development expenditure spending as a preferred policy choice by politicians is to enact policies that allow the median voter to invest in the modern sector. Reducing the fixed cost of accessing the modern sector and reducing wastage or corruption in infrastructure spending can achieve this. In addition, re-distributive policies that would lead to greater median voter wealth would also result in politicians providing more infrastructure investment. Because political parties will compete to provide the optimal policies preferred by the median voter, each of these policies will potentially allow infrastructure investment to be sustained in equilibrium.

The model above suggests a possible reason why SME investments - which we broadly interpret as modern sector investments - were historically concentrated in a few regions in India. This is because the returns to investing in the modern sector depend on both investments in infrastructure as well as an appropriate sectoral credit policy that reduces the fixed costs of accessing the modern sector. These insights are consistent with the findings of the recent World Bank Development Policy Review which notes that credit markets show considerable evidence of market failure in India and that "the vast majority of India's rural poor still do not have access to formal finance" (World Bank Development Policy Review 2006, p. 135). This suggests that the relevant policy bundle is one where infrastructure spending is made in conjunction with a relevant credit policy that reduces the fixed costs of investing in the modern sector.

There is ample evidence that there is rampant and institutionalized corruption, especially in the lower and middle rungs of government in India. Because of ineffective accountability mechanisms, there is enormous leakage in the implementing of public investment programs (World Bank Development Policy Review 2006). Joshi and Little (1996) note that a large number of workers in the public sector are also redundant with "disappointingly little productive employment being generated" (p. 192). In terms of cross country evidence, Davoodi and Tanzi (1997) show that corruption connected with public investment projects leads to a lower quality of public infrastructure. The model suggests that reducing corruption may not only have the standard efficiency-enhancing effect on growth by raising quality improving public investments, but by increasing the return to investing in the modern sector, reducing leakages from development expenditures allows higher infrastructure investment to be sustained endogenously. In particular, reducing the leakage of funds earmarked for public investment would induce politicians to spend more on public investment and less on unproductive subsidies.

Finally, an additional channel that determines the location of infrastructure investment but which is not considered here is the role of "agglomeration effects". Because infrastructure investments are characterized by both economies of scale and scope, such "agglomeration" 
effects would be another factor favoring the location of infrastructure investments in leading regional economies (Rodrik 1997).

\section{Acknowledgments}

I thank Arpita Chakraborty for excellent research assistance. I am grateful to Kunal Sengputa for many helpful comments. I also thank seminar participants at the 2007 TIES Meetings (IIT Bombay), the 2007 CIBS Conference in WIDER, Helsinki, and the EGP Group at the Max Planck Institute for Economic Research, Jena for helpful suggestions. The author is grateful to the ISI PPRU Committee for financial assistance related to this project. I remain responsible for any errors or omissions.

\section{References}

Bandopadhyay, S., 2004. Twin peaks - distribution dynamics of economic growth across Indian states. In: A. Shorrocks and R. van der Hoeven, eds. Growth, inequality and poverty: prospects for pro-poor growth. Oxford: Oxford University Press.

Barro, R., 1990. Government spending in a simple model of endogenous growth. Journal of Political Economy, 98, 103-125.

Dasgupta, D., et al., 2001. Growth and interstate disparities in India. Economic and Political Weekly, 1 July, 2413-2422.

Datta, G. and Ravallion, M., 2002. Is India's economic growth leaving the poor behind? Journal of Economic Perspectives, 16, 89-108.

Davoodi, H.R. and Tanzi, V., 1997. Corruption, Public Investment, and Growth. IMF Working Paper No. 97/139, 1-23.

Economic and Political Weekly Dataset, 2003. Mumbai: EPW Research Foundation.

Galor, O. and Zeira, J., 1993. Income distribution and macroeconomics. Review of Economic Studies, 60, $35-52$.

Holmstrom, B. and Tirole, J., 1997. Financial intermediation, loanable funds, and the real sector. Quarterly Journal of Economics, 112, 663-691.

Joshi V. and Little, I.M.D., 1996. India's economic reforms. New Delhi: Oxford University Press.

Marjit, S. and Mitra, S., 1996. Convergence in regional growth rates: Indian research agenda. Economic and Political Weekly, 17 August, 2239-2242.

Mauro, P., 1995. Corruption and growth. Quarterly Journal of Macroeconomics, CX 3, 681-712.

Rodrik, D., 1997. Has globalization gone too far? Washington, DC: Institute for International Economics.

World Bank Development Policy Review, 2006. New Delhi: Macmillan India. 
Copyright of Journal of Economic Policy Reform is the property of Routledge and its content may not be copied or emailed to multiple sites or posted to a listserv without the copyright holder's express written permission. However, users may print, download, or email articles for individual use. 